\title{
O REALISMO CIENTÍFICO E O ARGUMENTO DA SUBCONSIDERAÇÃO
}

\author{
SCIENTIFIC REALISM AND THE ARGUMENT OF UNDERCONSIDERATION
}

\author{
Marcos Rodrigues da Silva* \\ Gabriel Chiarotti Sardi**
}

\section{RESUMO}

De acordo com o filósofo realista Peter Lipton, cientistas, em sua construção de hipóteses, não consideram todas as alternativas possíveis para a explicação da ocorrência de um fenômeno. Sua tese deu origem a um problema denominado de argumento da subconsideração: se nem todas as hipóteses possíveis foram desenvolvidas, não se poderia falar que a hipótese eleita como melhor explicação de um fenômeno poderia ser considerada verdadeira. A resposta de Lipton foi que as alternativas não consideradas colidiam com o conhecimento anterior consolidado, e exatamente por isso não foram consideradas; ou seja: há uma dificuldade na produção de alternativas que é típica da própria prática científica. Além disso, para Lipton, a teoria que emerge da competição de alternativas pode ser considerada a melhor explicação de um fenômeno, e com isso o realismo científico é a concepção filosófica mais adequada para lidar com disputas entre hipóteses e também a mais próxima da prática científica. O objetivo deste artigo é mostrar que a relação estabelecida por Lipton entre a dificuldade da produção de hipóteses e o realismo científico não é uma relação necessária, visto existirem outras concepções (das quais uma delas será examinada neste artigo - a concepção de problemas anômalos de Larry Laudan) que, apesar de admitirem a restrição na produção de hipóteses, não podem ser consideradas realistas.

PALAVRAS-CHAVE: realismo científico; Peter Lipton; inferência da melhor explicação; argumento da subconsideração; antirrealismo.

\section{ABSTRACT}

According to the realist philosopher Peter Lipton, scientists, while are developing hypotheses, not taking into account all possible alternatives for the explanation of the occurrence of a phenomenon. His idea gave rise to a problem called the subconsideration argument: if not all possible hypotheses were developed, it could not be said that the hypothesis chosen as the best explanation of a phenomenon could be a true one. Lipton's reply was that the alternatives that were not considered collided with background knowledge, and this explains why they were not considered; that is: there is a difficulty in producing alternatives that is normal of scientific practice itself. Besides, for Lipton, the theory that emerges from the competition of alternatives can be considered the best explanation of a phenomenon and then scientific realism is the philosophical conception most suitable to deal with disputes between hypotheses and also it is closest to scientific practice. The purpose of this paper is to show that the relationship established by Lipton between the difficulty of producing hypotheses and scientific realism isn't a necessary relationship, since there are other conceptions (one of which will be examined in this paper - Larry Laudan's conception of anomalous problems) that, despite to acknowledge the restriction in the production of hypotheses, cannot be considered realistic.

KEYWORDS: Scientific realism. Peter Lipton. Inference to the Best Explanation. Argument of underconsideration. Anti-realism.

\footnotetext{
* Mestrado em Filosofia pela Pontifícia Universidade Católica do Rio Grande do Sul e doutorado em Filosofia pela USP. Professor da Universidade Estadual de Londrina. E-mail: mrs.marcos@uel.br.

** Mestrando em Filosofia pelo Programa de Pós-Graduação em Filosofia da Universidade Estadual de Londrina (UEL). E-mail: gabrielchi@ hotmail.com.
} 


\section{INTRODUÇÃO}

Em seu artigo Is the best good enough?, o filósofo realista ${ }^{1}$ Peter Lipton procurou tratar de algumas objeções ao célebre argumento da inferência da melhor explicação (doravante IBE - inference to the best explanation), forma essa de raciocínio que se tornou vital na defesa realista de que a explicação filosófica do sucesso da ciência não pode suprimir o conceito de verdade.

O argumento, na versão de Lipton, pode ser assim apresentado:

De acordo com a Inferência da Melhor Explicação, nossas práticas inferenciais são governadas por considerações explicativas. A partir de nossos dados e de nossas crenças anteriores, inferimos o que, se verdadeiro, forneceria a melhor das explicações rivais que podemos gerar daqueles dados [...] (LIPTON, 2004, p. 56, tradução nossa) $)^{2}$.

Esse argumento foi criticado pelo filósofo empirista construtivo e antirrealista Bas van Fraassen, e por outros. Dentre as várias críticas apresentadas por van Fraassen à IBE, uma delas foi analisada por Lipton, por este denominada de "argumento da subconsideração"3, o qual é assim formulado: i) podemos comparar confiavelmente teorias já formuladas; ii) mas como só podemos comparar teorias já formuladas (e não teorias possíveis), então é possível que exista uma teoria verdadeira mas que não tenha sido inserida no processo seletivo; iii) logo, não é possível termos conhecimento de que, em um processo de comparação de teorias, a teoria eleita é de fato a melhor explicação ${ }^{4}$. A conclusão geral que Lipton extraiu da crítica

\footnotetext{
${ }^{1}$ Em linhas gerais, o realismo científico é a concepção de que as teorias científicas bem-sucedidas fornecem boas razões para acreditarmos em sua verdade; uma posição antirrealista não nega que as teorias sejam bemsucedidas, mas não emprega o conceito de verdade para explicar filosoficamente esse sucesso.

${ }^{2}$ A formulação de Lipton de IBE é diferente da formulação original de Gilbert Harman (1965, p. 89). Essa diferença não importa aos propósitos deste artigo. Para discussões sobre a diferença na formulação, consultar Campos (2011).

${ }^{3}$ Este argumento é também conhecido como "argumento do conjunto defeituoso" (bad lot argument) (PSILLOS, 2000) e aparece em van Fraassen (1989, p. 142-143).

${ }^{4}$ O longo enunciado de Lipton do argumento da subconsideração é o seguinte: "Este argumento possui duas premissas. A premissa da classificação (ranking premise) enuncia que o teste de teorias acarreta apenas uma garantia comparativa. Os cientistas podem classificar, com relação à probabilidade da verdade, as teorias em competição por eles produzidas. A premissa concede que este processo é conhecido por ser altamente confiável, de modo que a teoria mais provável é sempre classificada à frente de uma rival menos provável, e a teoria verdadeira, se está entre as teorias produzidas, deve ser classificada em primeiro lugar, mas a garantia permanece comparativa. Em resumo, o teste habilita os cientistas a afirmar quais das teorias rivais que eles produziram provavelmente sejam corretas, mas não os habilita a divulgar quão provável é a teoria mais provável. A segunda premissa do argumento, a premissa da ausência de privilégio (no-privilege premise), enuncia que os cientistas não têm razões para supor que o processo pelo qual eles produzem teorias para testes torna provável que uma teoria verdadeira esteja entre aquelas que foram produzidas. Permanece sempre possível que a verdade esteja entre outras teorias que ninguém tenha considerado, e não existe forma de julgar o quão provável isto seja. A
} 
presente no argumento da subconsideração é a de que ela nos alerta para a natureza comparativa da avaliação entre teorias; com isso, não temos uma avaliação absoluta e, assim, epistemologicamente, não estamos garantidos em crer na teoria que ofereceu a melhor explicação. Estamos, portanto, diante de um problema: como enfrentar o argumento da subconsideração?

A solução apresentada pelo autor é a de que a exigência de van Fraassen pode ser atendida não por meio de uma proliferação infinita de teorias alternativas, mas por meio das virtudes internas (sem desconsiderar, é claro, sua relação com a realidade natural) das próprias teorias, não importando o número de alternativas que estejam em competição. Assim, na primeira seção deste artigo, apresentaremos a solução de Lipton ao problema mencionado, a qual consideramos satisfatória (por razões que serão explicitadas nesta primeira seção).

A solução de Lipton ao desafio imposto pelo argumento da subconsideração possui, entretanto, dois pressupostos, dentre os quais apenas um foi enunciado explicitamente pelo filósofo. O primeiro pressuposto de Lipton (2010, p. 321-322) é o de que sua solução ao argumento da subconsideração nos coloca diante da prática científica real: efetivamente, na busca de uma explicação, não são consideradas todas alternativas possíveis (sobretudo pelo fato de que algumas violariam o conhecimento já consolidado).

Já o segundo pressuposto, não enunciado por Lipton, é o da dificuldade na produção de alternativas rivais para integrarem o conjunto de teorias a serem avaliadas (e selecionadas) pelos cientistas. Não é incomum, quando examinamos a literatura da filosofia da ciência, encontramos exemplos abstratos de um conjunto de teorias em competição, em enunciados como: "dadas as teorias T1, T2 e T3 ......”. Porém é digno de nota que a prática real nem sempre registra tal proliferação, estando disponíveis, na literatura historiográfica da ciência, episódios históricos que exemplificam a complexidade existente no processo de produção e seleção de alternativas. Evidentemente, Lipton não ignorou esse fato; todavia, do mesmo modo, não o explorou.

E por que Lipton não o fez? Trabalha-se aqui com uma hipótese: levar às últimas consequências o primeiro pressuposto - ou seja: não se consideram todas as alternativas possíveis - significa ter de abrir mão de alguns princípios realistas (por exemplo, o princípio

conclusão do argumento é a de que, a despeito de a melhor das teorias produzidas poder ser verdadeira, os cientistas nunca possuem boas razões para acreditar nisto. Eles sabem qual das teorias rivais que eles testaram provavelmente seja a verdadeira, mas eles não sabem como julgar a probabilidade de que qualquer destas teorias o seja. Nesta perspectiva, acreditar que a melhor teoria disponível seja verdadeira seria como acreditar que Jones vencerá as Olimpíadas, quando tudo que se sabe é que ele é o fundista mais rápido na Inglaterra." (LIPTON, 2010, p. 314). 
de que sempre escolhemos a melhor de todas as alternativas possíveis). Temos, portanto, como objetivo do presente artigo, desenvolver o segundo pressuposto elencado, a ser alcançado na segunda seção deste artigo: desenvolver o segundo pressuposto de Lipton por meio de uma argumentação que nem sempre atenderá as exigências realistas. Ou seja: esperase mostrar que o caminho trilhado por Lipton para criticar o antirrealismo do argumento da subconsideração pode conduzi-lo para estruturas conceituais não completamente realistas. E, de modo a desenvolver nossa hipótese, empregaremos, ainda na segunda seção, a noção de “problemas científicos” apresentada por Larry Laudan. De acordo com Laudan, um tipo específico de problema científico (problemas anômalos) somente emerge no interior de um quadro conceitual já vigente.

Em um primeiro momento, aparentemente, podemos identificar conceitualmente as noções de conhecimento anterior de Lipton e problemas anômalos de Laudan como restrições ao surgimento de novidades, porém isto não estaria de acordo com as construções filosóficas de ambos os filósofos. Embora os dois filósofos coloquem restrições ao surgimento de novidades, essas restrições não são as mesmas. Para Lipton, o conhecimento anterior é de fato uma restrição; já para Laudan, a restrição é mais branda, no sentido de que uma solução a uma anomalia não necessariamente se pautaria pelo conhecimento anterior.

Por fim, na conclusão, argumenta-se a favor da contribuição de Lipton para a compreensão do conhecimento científico, sobretudo das limitações da produção de alternativas rivais. Porém, argumenta-se também que a contribuição de Lipton, originalmente articulada como uma defesa de uma interpretação realista do sucesso da ciência, pode ser assimilada por outras perspectivas filosóficas que não podem ser entendidas como completamente realistas.

\section{A RESPOSTA DE LIPTON AO ARGUMENTO DA SUBCONSIDERAÇÃO}

Em um primeiro momento, o argumento da subconsideração, por ser um desafio cético, parece não poder ser enfrentado. Suponha-se, de forma abstrata, que possuímos as teorias T1, T2 e T3 como alternativas e que escolhemos T1. De acordo com o argumento da subconsideração, não podemos saber que inferimos a melhor explicação, pois poderia haver outras alternativas (T4, T5 e assim por diante). Como argumenta van Fraassen (1989, p. 142143 , tradução nossa):

Sapere aude - Belo Horizonte, v. 12 - n. 23, p. 148-159, Jan./Jun. 2021 - ISSN: 2177-6342 


\begin{abstract}
Admitamos que os cientistas tenham disposto um conjunto de teorias T1..., Tn, sendo que todas elas oferecem potenciais explicações da evidência $e$, e tenham escolhido como a melhor explicação de e, digamos, T1. Para que eles afirmem que T1 é a explicação aproximadamente verdadeira de e, eles devem dar 'um passo além com relação ao juízo comparativo de que [T1] é melhor do que suas rivais atuais'. Eles devem dar um 'passo ampliativo'. Este passo envolve a crença de que a verdade provavelmente já esteja presente dentro do conjunto de teorias disponíveis aos cientistas, mais do que a crença de que a verdade não estaria presente no conjunto. Não obstante, nossa melhor teoria talvez seja 'a melhor de um conjunto defeituoso'. Portanto, para que o defensor de IBE sustente que ela nos conduz à verdade, ele deve assumir um Princípio de Privilégio. Isto é, ele deve assumir que 'a natureza nos predispõe a encontrar a série certa de hipóteses'.
\end{abstract}

Contudo, é salutar ressaltar que, para van Fraassen, não há razão para sustentar a racionalidade de tal princípio de privilégio, visto não termos segurança absoluta de que a natureza nos predispôs a estarmos diante do conjunto que contém a hipótese verdadeira.

Assim, se o argumento da subconsideração de van Fraassen se estabelece, o máximo que poderemos obter, usando os termos de Lipton, é uma avaliação comparativa, e não uma avaliação absoluta das teorias disponíveis e selecionamos, meramente, a melhor do conjunto (que não possui garantia absoluta de conter a hipótese verdadeira), e não exatamente uma teoria passível de crença em sua verdade.

De acordo com Lipton, aparentemente, então, os cientistas teriam de ser capazes de produzir todas alternativas logicamente possíveis, o que é virtualmente impossível (LIPTON, 2010, p. 319). E, acrescentamos, não apenas virtualmente impossível, mas logicamente infrutífero para a discussão: após os cientistas terem produzido todas as alternativas, ainda seria possível argumentar que uma nova alternativa poderia ser produzida ${ }^{5}$.

O problema colocado pelo argumento da subconsideração é então o de que o número de alternativas é sempre insuficiente; isto é, nunca um cientista tem em mãos a garantia efetiva de que possui a alternativa explicativa correta dentre o conjunto de hipóteses analisadas $^{6}$, visto que é sempre logicamente possível elaborar uma outra explicação que difira da anterior. É neste ponto que Lipton modifica substancialmente a discussão.

\footnotetext{
${ }^{5}$ Argumenta Lipton (2010, p. 319): “A forma mais direta de eliminar a lacuna entre avaliação comparativa e absoluta seria por exaustão. Se o cientista pudesse produzir todas rivais possíveis no domínio relevante, e ele soubesse disso, então ele saberia que a verdade está entre elas. Dada a confiabilidade que a premissa da classificação concede, ele também saberia que a melhor das rivais é provavelmente verdadeira. Esta solução baseada na força bruta, no entanto, parece inadequada, pois adota uma perspectiva insensatamente exagerada das habilidades do cientista. Mesmo admitindo-se que podemos tornar significativa a noção de todas rivais possíveis, como poderiam os cientistas possivelmente produzi-las todas?"

${ }^{6}$ Por essa razão, conforme salientado anteriormente, o argumento da subconsideração também é chamado de "argumento do conjunto defeituoso".
} 
Suponha, argumenta Lipton, uma única teoria disponível para explicar um fenômeno. Em um primeiro momento, nem mesmo poderíamos falar de "melhor" explicação, pois o emprego do termo melhor exige comparação. Ocorre, no entanto, que não existem outras alternativas disponíveis para análise. Porém, suponha adicionalmente, prossegue Lipton, que essa teoria seja considerada verdadeira para um cientista e que ela de fato explique os fenômenos. Se esse cientista se orientasse pelo problema gerado pelo argumento da subconsideração, ele não poderia apresentar sua teoria para a comunidade científica - e nenhuma explicação poderia ser oferecida. No entanto, acrescenta Lipton, o cientista pode comparar as afirmações de sua teoria (por ele considerada verdadeira) com o contrário das afirmações da própria teoria e analisar as consequências derivadas da hipótese contrária. Vejamos um exemplo hipotético.

A teoria $\mathrm{T}$ afirma $\mathrm{X}$; não há outra teoria para contradizer $\mathrm{T}$ (e, portanto, contradizer $\mathrm{X})$. Mesmo assim, afirma Lipton, o cientista que afirma $\mathrm{X}$ pode comparar $\mathrm{X}$ com sua negação (isto é, $\neg X)$. Assim, se X significa, por exemplo, "existem elétrons", o cientista compara X com sua negação $\neg X$, que por sua vez será a afirmação "não existem elétrons" e procura vislumbrar quais seriam as consequências gerais de uma afirmação com esse teor de conteúdo epistêmico tanto para o conhecimento científico como um todo, quanto aos fatos do mundo.

\footnotetext{
Basta que o cientista considere uma teoria e sua negação, ou a afirmação de que uma teoria tem uma probabilidade maior do que a metade e a afirmação de que ela não o tem, ou a afirmação de que $\mathrm{X}$ é a causa de algum fenômeno e a afirmação de que não o é, ou a afirmação de que uma entidade ou processo com propriedades especificadas existe ou não existe. (LIPTON, 2010, p. 319).
}

Desse modo, a exigência de proliferação teórica contida no argumento da subconsideração não se sustentaria, dados os méritos intrínsecos da única teoria disponível e da comparação dessa teoria com o contrário do que ela própria afirma. Porém, o que é mais importante ainda é que a própria exigência de proliferação, mesmo sem a questão lógica envolvida (a de que sempre seria possível se exigir uma nova alternativa), se torna enfraquecida (ou pode inclusive ser abandonada).

A rejeição de Lipton ao argumento da subconsideração se torna ainda mais robusta se pensarmos em sua teoria da explicação científica. De acordo com Lipton, inferências (acerca de uma teoria ser a melhor explicação de um conjunto de fenômenos) são produzidas por finalidade explicativa (LIPTON, 2004, p. 55). Cientistas são movidos pelo desejo de explicação e, se i) a construção de uma explicação está seguindo uma direção aceitável, 
coerente com o conhecimento já consolidado, adotando procedimentos metodológicos confiáveis etc. e, ii) se ao fim da construção dessa explicação foi obtido um resultado plausível, então iii) uma inferência da melhor explicação foi efetivamente obtida. Mesmo porque, como Lipton afirma, uma inferência só pode ser produzida se for suficientemente boa (LIPTON, 2004, p. 63). Evidentemente, a teoria inferida como melhor explicação pode ser criticada (seja imediatamente, seja posteriormente), mas, quanto ao processo inferencial ${ }^{7}$, ela cumpriu os requisitos inferenciais exigidos - e é este atendimento às exigências que solapa o argumento da subconsideração, pois garante que todas as alternativas razoáveis disponíveis até então foram analisadas por meio da comparação do núcleo epistêmico da negação da hipótese explicativa em questão.

Lipton assinala também uma incoerência no argumento da subconsideração. Lembremo-nos da premissa (i) do argumento: podemos comparar confiavelmente teorias já formuladas. Ora, considerando a prática científica real (LIPTON, 2010, p. 321-322) — na qual hipóteses estranhas ao quadro conceitual vigente (estranhas ao conhecimento consolidado) são em geral eliminadas, pois não agregam confiabilidade aos procedimentos metodológicos empregados pelos cientistas —, então a premissa (i) do argumento da subconsideração seria falsa, pois os cientistas não seriam classificadores confiáveis. Isso, contudo, é negado pelo próprio van Fraassen (1989, p. 129), para quem o contexto determina quais hipóteses devem ou não ser desenvolvidas para a explicação de um fenômeno; ou seja: o próprio van Fraassen admite alguma confiabilidade quanto à classificação de hipóteses que devem ser consideradas.

Encerrando a seção, concluímos que Lipton parece ter excelentes razões para rejeitar o argumento da subconsideração. Vejamos agora algumas consequências dessa rejeição e se essa rejeição necessariamente conduz ao realismo científico.

\footnotetext{
${ }^{7}$ Apesar de não ser o ponto central do presente artigo, se faz conveniente evidenciar que, embora seja comum encontrarmos na literatura de filosofia da ciência (inclusive nos escritos do próprio Lipton (2004) a identificação entre os conceitos de "abdução" e "inferência da melhor explicação", tais formas de raciocínio não são exatamente os mesmos processos inferenciais). De acordo com Campos (2011), a abdução, da forma como foi elaborada por Charles S. Peirce, trata-se de um processo cognitivo que apresenta uma hipótese completamente nova na forma de um insight, seja criando uma alternativa inédita ou reinterpretando algo já conhecido; enquanto IBE, sobretudo da forma como foi apresentada e desenvolvida por Lipton, remete a um processo seletivo entre hipóteses rivais baseado nas considerações explicativas das alternativas (mesmo que possa incluir ou sugerir hipóteses novas no processo seletivo). Dessa forma, portanto, IBE e abdução são processos completamente distintos. "Nesse caso, é seguro concluir que, pelo menos em um sentido substancial, abdução e IBE são claramente distintas: abdução é para geração de hipóteses ou teorias, enquanto IBE é para avaliá-las." (PARK, 2017, p. 31, tradução nossa).
} 


\section{AS CONSEQUÊNCIAS DA CRÍTICA AO ARGUMENTO DA SUBCONSIDERAÇÃO}

Aceitando-se a crítica de Lipton ao argumento da subconsideração, vejamos agora possíveis consequências do alcance dessa crítica.

Um dos pontos decisivos da crítica de Lipton foi sua menção à prática científica real: cientistas não consideram todas as possibilidades. Essa tese, porém, não é uma exclusividade dos realistas científicos. Nem todas as ocorrências fenomênicas são tratadas como problemas científicos (LAUDAN, 2010, cap. 1); nem todas as anomalias são levadas em consideração pelos cientistas (KUHN, 2011); alternativas rivais, mesmo reais e conhecidas, nem sempre são levadas em consideração pelos cientistas (STANFORD, 2006, cap. 2); nem todas as sentenças científicas são desenvolvidas, pois não se relacionam com outras sentenças (LATOUR, 2000, p. 35). Em outros termos: não é exatamente uma tarefa fácil produzir alternativas rivais. Isso, a propósito, é reconhecido pelo próprio Lipton, no entanto, ele não desenvolve essa ideia (de que não é uma tarefa fácil produzir alternativas rivais).

Trabalharemos aqui com uma hipótese de por que Lipton não desenvolveu sua crítica: levar às últimas consequências a concepção de que é difícil produzir alternativas significa ter de abrir mão de alguns princípios realistas (por exemplo, o princípio de que sempre escolhemos a melhor de todas as alternativas possíveis). E, de modo a desenvolver nossa hipótese, empregaremos aqui a noção de "problemas científicos" apresentada por Larry Laudan.

De acordo com Laudan (2010, p. 20), uma teoria deve ser levada em consideração se apresentar "respostas aceitáveis a perguntas interessantes: em outras palavras, se oferece soluções satisfatórias a problemas importantes". (Essa exigência está em perfeita consonância com a fórmula de Lipton de que uma teoria é a melhor apenas se for suficientemente boa). Assim, não é qualquer fenômeno que merece investigação (LAUDAN, 2010, p. 23), e, portanto, podemos concluir que uma teoria que aborda um fenômeno desinteressante não merecerá consideração, pois não estará tratando de um problema importante: "Em qualquer momento da História da Ciência, muitas coisas serão vistas como fenômenos bem conhecidos, mas não se sentirá a necessidade de explicá-los ou esclarecê-los.” (LAUDAN, 2010, p. 25).

Para Laudan, existem dois grandes tipos de problemas: empíricos e conceituais, dos quais nos interessa o primeiro tipo. Os problemas empíricos, por sua vez, se subdividem em 
problemas não resolvidos, problemas resolvidos e os problemas anômalos. E é nesta subclasse — a dos problemas anômalos —, que buscamos subsídios para nossa discussão.

Uma anomalia, grosso modo, é uma ocorrência fenomênica não prevista por uma teoria vigente. Suponhamos que uma teoria T não explique a anomalia; para Laudan, isso não é razão nem para abandonarmos T (LAUDAN, 2010, p. 39) e nem para admitirmos que haja um problema a ser resolvido por T (p. 41). Porém, imaginemos que uma teoria rival T1 explique a anomalia; ora, nesse caso, a anomalia passa a ser um problema para $T$ (p. 43): "um problema só pode ser tido como anômalo para uma teoria se for resolvido por outra", pois revela uma lacuna ou ineficiência da teoria $\mathrm{T}$ diante de um problema que merece ser digno de atenção e passível de resolução pela rival T1.

Um outro ponto importante salientado por Laudan (2010, p. 53) é o do reconhecimento (ou ausência de reconhecimento) da importância cognitiva de uma anomalia. (Laudan parte aqui do pressuposto, largamente suportado pelo registro histórico, de que quase todas as teorias bem-sucedidas se deparam com anomalias.) Porém, essa importância é relativa, isto é, relativa à existência de uma teoria rival que tenha solucionado a anomalia. Como argumenta Laudan (2010, p. 52-53):

\begin{abstract}
Se uma teoria for a única conhecida em determinado campo, pode haver dúzias de casos de 'refutação', e provavelmente nenhum deles será de importância decisiva. Afinal, quando perguntamos sobre a importância da anomalia, estamos fazendo a seguinte pergunta: até que ponto tal anomalia deveria nos levar a abandonar a teoria que a gerou? [...] na ausência de uma sucessora, este seria um fracasso cognitivo.
\end{abstract}

E, com isso, prossegue Laudan (2010, p. 54): "avaliar a importância de qualquer problema aparentemente anômalo é algo que deve ser feito no contexto das outras teorias concorrentes naquela área”.

Apresentadas essas estruturas básicas do tratamento de Laudan aos problemas anômalos e sua noção de tradição de pesquisa, retornemos agora à resposta de Lipton ao argumento da subconsideração, mantendo o diálogo com a concepção apresentada por Laudan.

Assumida a estrutura conceitual de Laudan sobre o significado dos problemas anômalos, não restam dúvidas de que ele concordaria com Lipton a respeito de que nem tudo deve ser considerado (no caso de Lipton, na busca de uma inferência da melhor explicação). Mas há diferenças importantes, que incidem diretamente na solução de Lipton ao argumento da subconsideração, especificamente quanto ao seu realismo. 
Conforme já vimos, para Lipton, inferir que uma teoria é a melhor explicação só é possível se essa teoria melhor é suficientemente boa (no caso de Lipton, uma teoria explicativamente plausível e verdadeira). Lipton também concordaria com Laudan (como vimos na seção 1) que a ausência de rivais não é uma ameaça para a manutenção de uma teoria (Laudan) ou para inferir que ela é a melhor explicação (Lipton).

A questão, a partir de agora, é a de verificar o alcance realista da crítica de Lipton ao argumento da subconsideração.

O núcleo da crítica de Lipton é bastante simples: nem tudo pode ser considerado quando se busca a melhor explicação. A principal razão oferecida por Lipton é a de que hipóteses sem conexão com o conhecimento consolidado não deveriam ser levadas em consideração. Nesse caso, Lipton está efetivamente colocando um critério para a aceitação de hipóteses que podem ser consideradas. Mais do que isso: trata-se de uma orientação efetivamente realista. Como argumenta Lipton: "Estas teorias de fundo são, em si mesmas, o resultado de uma produção e classificação prévias, e a melhor das teorias que agora está sendo classificada constituiria parte do background de amanhã." (LIPTON, 2010, p. 322) ${ }^{8}$.

Qual seria, para Laudan, um critério para a consideração de uma teoria alternativa? Como já vimos, uma teoria somente será considerada se resolver um problema anômalo não resolvido por uma teoria vigente. Em segundo lugar, Laudan não está exigindo que essa nova teoria que resolveu o problema anômalo (não resolvido pela teoria vigente) tenha conexão com o conhecimento anterior (e, por conseguinte, sequer se coloca, a Laudan, a exigência liptoniana de que o conhecimento anterior seja verdadeiro). Vejamos um exemplo da história da ciência que mostra claramente a diferença entre as abordagens de Lipton e Laudan quanto à restrição de proliferação de alternativas. O exemplo utilizado é extraído de Paul Thagard (2007), a respeito do confronto entre a teoria do flogisto (dominante na química até quase o final do século XVIII) e a nova química de Lavoisier (surgida no final da década de 80 do século XVIII).

De acordo com Thagard, a concepção química de Lavoisier não foi considerada até 1783, ano em que apresentou um novo esquema conceitual (THAGARD, 2007, p. 280). Até esse momento, Lavoisier não tinha em seu repositório teórico um conhecimento anterior verdadeiro, o que explica, em termos liptonianos, sua desconsideração. (A propósito, tal desconsideração foi fomentada pelo próprio Lavoisier, que sabia que não poderia substituir a

\footnotetext{
${ }^{8}$ A expressão "teorias de fundo" refere-se ao conhecimento anterior consolidado.
} 
teoria do flogisto sem uma alternativa robusta - visto que a tradição de pesquisa do flogisto orientava os químicos há mais de um século).

A teoria do flogisto se deparou com uma anomalia; segundo o arcabouço teórico da tradição flogística, quando ocorria uma combustão, o flogisto (o princípio da combustão) seria liberado. No entanto, durante o desenvolvimento dos trabalhos de Lavoisier, o químico Guyton de Morveau conduziu experimentos que mostravam que em uma combustão o material aquecido ganhava peso, o que poderia sugerir que não havia perda de flogisto. Ocorre, entretanto, que em um primeiro momento não surgiu uma alternativa à teoria do flogisto e, à vista disso, a teoria do flogisto se manteve até o momento em que Lavoisier finalmente apresentou sua nova química.

Assim, por meio da concepção de Laudan, entendemos também por que uma alternativa à teoria do flogisto deveria ter sido desconsiderada, desde que não fosse uma alternativa razoável que explicasse satisfatoriamente tanto os fenômenos já abarcados pela teoria do flogisto, quanto esse fenômeno peculiar. Porém note-se que, ao contrário de Lipton, Laudan não necessita da concepção de conhecimento anterior (e, é óbvio, não necessita da noção de conhecimento anterior verdadeiro) para explicar esse episódio específico da história da ciência.

\section{CONCLUSÃO}

Tanto Laudan quanto Lipton estão apresentando razões filosóficas para a desconsideração de alternativas e, portanto, podemos afirmar que ambos estão enfrentando o problema colocado pelo argumento da subconsideração. $\mathrm{O}$ que procuramos apontar foi que o realismo não é indispensável para tal enfrentamento, conforme ficou evidente diante da resposta elaborada com base nos conceitos laudanianos.

Evidentemente, reconhecemos i) que Lipton (do mesmo modo que Laudan) está oferecendo uma notável contribuição para um entendimento do funcionamento da prática científica; e reconhecemos também ii) que o enfrentamento ao argumento da subconsideração emergiu no interior da filosofia realista, e isto precisa ser ressalvado por razões históricas. Entretanto, nem (i) nem (ii) e tampouco a rejeição ao argumento da subconsideração nos conduzem a uma aceitação do realismo científico. 


\section{REFERÊNCIAS}

CAMPOS, Daniel. On the distinction between Peirce's abduction and Lipton's Inference to the best explanation. Synthese, v. 180, n. 3, 2011.

HARMAN, Gilbert. Inference to the best explanation. The Philosophical Review, v. 74, n. 1, 1965.

KUHN, Thomas. A estrutura das revoluções científicas. 10. ed. Tradução de Beatriz V. Boeira e Nelson Boeira. São Paulo: Perspectiva, 2011.

LATOUR, Bruno. Ciência em ação. Tradução de Ivone C. Benedetti. São Paulo: Editora UNESP, 2000.

LAUDAN, Larry. O progresso e seus problemas: rumo a uma teoria do crescimento científico. Tradução de Roberto Leal Ferreira. São Paulo: Editora UNESP, 2010.

LIPTON, Peter. É o melhor bom o suficiente? Tradução de Marcos Rodrigues da Silva e Alexandre Meyer Luz. Princípios, v. 17, n. 27, 2010.

LIPTON, Peter. Inference to the best explanation. London: Routledge, 2004.

PARK, Woosuk. Abduction in context: the conjectural dynamics of scientific reasoning. Springer: 2017.

PSILLOS, Stathis. Sobre a crítica de van Fraassen ao raciocínio abdutivo. Tradução Marcos Rodrigues da Silva e Alexandrer Meyer. Revista Crítica, Londrina: UEL, 2000.

STANFORD, Kyle. Exceeding our grasp. Oxford: Oxford University Press, 2006.

THAGARD, Paul. A estrutura conceitual da revolução química. Tradução de Marcos Rodrigues da Silva. Princípios, v. 14, n. 22, 2007.

VAN FRAASSEN, Bas. Laws and symmetry. Oxford: Oxford University Press, 1989. 